\title{
Telepresence Robot: Process of Appropriation through the Evolution of the Modalities of Presence
}

\author{
Dorothée Furnon, Françoise Poyet \\ Laboratory E.C.P. Lyon - France
}

\begin{abstract}
Emergence of technologies of information and communication in higher education is reconfiguring pedagogical 'spaces and times. These technologies bring a new signification of concepts of the absence and the presence or whether the copresence of a student and a teacher. Previously, when the student's state of health prevented him to participate in normal schooling, this situation led him to a drop out or a grade repetition.

These technologies usher in an opportunity to allow these students to participate to traditional face-to-face learning through a new form of presence. Presence cannot be reduced to its physical dimension. Social Sciences researches underline the various dimensions of presence which relate to cognition, affect or social's aspects. Presence is made visible to others through internationals' abilities deployed in interaction with his environment. The topic of this research is to describe how a telepresence robot can provided a new form of presence and allow a student to participate to her face-to-face learning and its social life.

Through the Rabardel instrumental theory, we observe the way a hospitalized student, named Hormé, is appropriating this artifact during the instrumentation process to demonstrated forms of presence during the courses.

To observe and understand the signs of presence and its effects on learning process and pedagogical relationship, we have used an interactionist approach, expanded with post-activity interviews. The first results show how Hormé reorganized and stabilized her actions schemes and her cognition to participate to courses. Result show also how the commitment of teachers promotes learning process in the pedagogical relationship.
\end{abstract}

\section{Introduction}

The emergence of information and communication technologies in education leads to a reorganization of space and teaching time by rethinking the notion of presence and absence. Indeed, the theoretical knowledge is brought to be relocated outside of school walls; this movement is being made possible by hybridization of the working environment, either in terms of place or tool.
The use of digital in education offers a wide choice of learning devices which opens the way to new working methods; courses can take place in synchronous or asynchronous times, in face to face in the classroom or distance learning, outside the classroom.

Those innovative teaching formats recompose the terms of the presence and absence of actors. Distance learning by videoconference demonstrates this conception of presence-absence: teacher and learner are not together in the same place; however, their activity systems present a common activity whose action emerges from the interactions between the two interactants and is directed towards the same goal. Recent studies shows that despite the physical distance, learners feel more closeness with teacher as well as other learners during distance lesson that during classes in face to face in lecture formats amphitheater [1]. These data question the definition of the presence of the learner in class and how it is reflected in the learning process and its interactional dimension.

We work in a French engineering school, as a robot project manager for teaching. We are in charge of supporting the integration of these technologies in higher education institutions in our Region, corresponding to eleven universities and five colleges. This study is part of a thesis we are conducting and which deals with the use of telepresence robots in higher education.

We choose to explore the question of presence by analyzing the use of a telepresence robot by three students from three French universities, whose state of health or disability makes it difficult, even impossible, to go on to their university.

This robot is composed of a mobile videoconferencing system linked to wheels and remotely controllable by students (a more detailed description of the robot will be given in "Method" part). The main objective of telepresence designer is to offer a feeling of presence. The first definition of telepresence was given by Minsky: «The biggest challenge to develop telepresence is achieving that sense of "being there." Can telepresence be a true substitute for the real thing? Will we be able to couple our artificial devices naturally and comfortably to work together with the sensory mechanisms of human organisms?" [17]. This definition of presence refers to a subjective 
experience in which a person feels like being there, located in a place while she is in direct physical contact in another place. This is a form of being which goes beyond the natural laws governing space and time. The sensorial and perceptive dimension is emphasized. Therefore, users of this technology could receive information from a remote environment, but there is no reference to the use of the media. Telepresence experience must be lived as immediate and direct.

The media must be transparent and must give the perceptual illusion of non-mediation. Nevertheless, the observations we have made concerning robot's uses, shows that this robot modifies or even annihilates users from some perceptuals'actions.

In this study, we focus on the dimension of the use as defined by Proulx [18] with the aim to grasp how users can feel at one with the robot through an instrumentation process [19] coupled with the concept of extension of body mapping [16].

The first goal of this research is to apprehend the effects of this new form of presence in learning process and the way it evolves in the pedagogical relationship [11] in an instrumental process [19]. The second goal is to know under what conditions this device can be adapted for students whose medical condition prevents a physical presence in class.

Data collection is based on an interactionist and situated approach of activity. We conducted observations and recorded courses of the three students included in our study. Then, we led postactivity interviews with teachers and explicitations' interviews with the three students who used the robot.

While our study is not yet complete, preliminary results are providing some elements of understanding of how robot's instrumentation allows the student to manifested a form of presence in interaction with teachers and the whole group and actions also be made possible by this form of presence.

First, we will present the theoretical framework, going through the different concepts of presence and we will approach studies the place of body on presence and its importance in the construction of knowledge.

To understand how the use of this robot modified the presence of a student, we will support our understanding of the situation on the instrumental theory of Rabardel as well as the phenomenological approach of perception, in order to understand how students, away from their classroom, can experience the telepresence robot as an extended body, allowing them to act and to interact with remote environment.

After, we will introduce the telepresence robot and the method we used to collected data. Then, we will discuss the first results.

\section{Theoretical Framework}

\subsection{Dimensions of presence and the pedagogical relationship}

The reason why someone is in a given environment is due to literature and its elements of comprehension. Here we have a polysemous concept whose signification will differ with the context in which the concept is. In context of the chosen subject which is the higher education, the sense of the presence would diverges if its accounting concerns the management of materials of food resources, such as the school canteens, the water, the electricity or the different maintenance services. It also will take a different sense if it is seen from the point of view of the insurances or the one of the many security norms.

Finally, the presence in a classroom has many significations and, sometimes, contradictory significations. Actually, which teacher has never noticed when a student was physically present but mentally absent? So, it is well-known that the presence in a classroom can't be reduced just as a physical presence.

Jézégou [13] divide presence on three dimensions: cognitive, socio-emotional and, educational.

The cognitive presence forming part on the social constructivist approach is about the cognitive process used by individuals to solve a problem. This dimension underlies the negotiations and transactions between members of a learning community. This presence is an opportunity to create socio cognitive conflict during which learners compare their understandings, interpretations and representations of an element brought by the participants.

The cognitive presence facilitates the coconstruction of the knowledge which emerged from the interaction between the teacher and his students.

The second dimension is the socio-emotional presence which is made by the construction and the properties of the inter-individuals relations which take place in the learning process. This modality of presence corresponds to the climate in which transactions and interactions between the teacher and his students operate. This presence is conforming to the emotions which emerged during the teaching.

The structured socio-emotional presence in a caring context facilitates the manifestation of the cognitive presence.

The educative presence throw-back to the role played by the teacher, the accompanying group in the cognitive process but also in the orientation toward strategies and resources responding to the learner's difficulties. We can find this presence in interactions between the teacher and his students through singular 
activities such as "The conception, the facilitation and, the social and cognitive process to reach some personal, significant and interest of learning results by the educative way." [12]

This tri-dimension of the presence manifests itself through the interactions between the different actors. It is possible thanks to the exchanges, the multi-modality of communications [4], and intercomprehension. Therefore, Goodwin shows that individuals are going to use different ways to adjustment to understand each other by the intercomprehension and build an action [8].

Those interactions will be deployed in pedagogical relationship defined by Houssaye [11] such as the relationship between the teacher and the learner which takes shape during exchanges between them and mutual actions. The formation process evolve in this pedagogical relationship: it is built between the teacher and the student through the knowledge.

Even if the pedagogical relationship is asymmetrical, it is the interaction between classmates and the teacher that create social phenomena which underlines some cognitive, emotional but also behavior aspects. Here, the presence of the teacher is felt by actions whose effects are managed towards the learners. Those actions are adjusted, modified in situation and in confrontation to the understanding and subjectivity of learners. It is manifested among others by listening and a singular attention [10].

This relationship, even asymmetrical, then coconstructed in the interaction between teacher and learner. Multimodality of the presence but also the presence of learner and teacher, were the construction of knowledge and promotes learning.

We also considered that in "traditional" teaching, the co-presence is a fundamental aspect for the construction of knowledge. The student is going to transform and build significations to information transmitted in the pedagogical relationship by his corporeality and senses.

\subsection{The body's place in the construction of knowledge}

The students and the teacher's physical copresence can't be reduced to a kind of physical presence whose actions would be directly objectivables from the outside. This physical presence should go hand in hand with mind's actions and, cognitive and emotional acts which work as a filter to interpret and build meanings of the situation.

To apprehend the body's place in the construction of knowledge, we rely on the work carried in the field of phenomenology of perception [16]. In this approach, the individual is in the world through his body, his senses, his movements, his gestures and his affects. For all of these elements, its presence in the world is always that of a body in action. Indeed, perception is a mechanism which involves the sensory system that, by contact sensors located in the whole body will collect information send by environment and on the same time, will project knowledge and representations on the perceived object.

It is in the interaction between an individual and his environment that the perceptual system will give meaning about situation and then, will create knowledge. The student by his corporal presence, and so his perception, will interpret and construct meanings of the information he receives from his environment.

Lebreton [14] wrote that the body works like a sieve that will make an interpretation of the event. The body and sense of the student will give their significations to events. These interpretations go through a process that converts food coming from the outside to be integrated within. The environment, for the individual, is nothing other than what he perceives. Perception of the object is embodied and corporeally situated.

From a perception point of view, bodily space which corresponds to the body mapping is not limited to one's biologic body but it may also involve other spaces situated out of the body. Merleau-Ponty defines the body mapping as a positions system which could be open to other positions which may be outside, in the extracorporeal space. This extension of body mapping is made possible by the motor assimilation of the object situated in the extension of one's body and which becomes a sensitive area. The author illustrates this thesis with a blind person using a stick and who feels with the tip of his stick which becomes a sensitive area, analogous as his eyes.

This reflexive dimension is also found in the theory of enaction, developed by Maturana and Varela [15]. According to the author, the world's understanding emerges in a structural coupling between the system and its environment. Knowledge is then constructed in the interaction with the environment. Enaction corresponds to the history of structural coupling that makes emerge the world. The body cannot be separated from its surroundings, if we wish to understand how knowledge is constructed, it is necessary to look at the history of the coupling of the individual and the world with which it interacts.

The person's body and mind will test utilization schemes by initiating them on the environment and those reactions will participate to the selection and 
development of schemes more useful to maintain this system. "This is what we called enaction: on the one hand the "enacted" system make its environment "emerged" from schemes which results of its interne organization; on the other hand, the system "enacted" itself from reactions of this environment to the actions from those schemes" [5] The construction of knowledge is part of an interactional dynamics between the student and his environment.

This construction of the knowledge takes part of a dynamic interactional between the student and his environment. The person by his physical presence develops interactional skills which allow an intercomprehension of the situation and the action supporting the construction of the knowledge.

We use the notion of interactional skill as it is defined by Garfinkel: "By skills, I mean the knowledge they have of the situations, their ability to deal with it and the fact that they have the quality to do the activity" [7]. It corresponds to the person capacity to act in function of the situation and to produce significant actions beside members of the group.

The presence of the learner gives some skills about interactional knowledge deployed in the teaching and social skills which passed by the development of schemes dealing with the movement, the gesture and multi-modality of the communication. Those interactional skills allow the interpretation of information spread in the environment.

Those skills are built in the interaction and in the contextualization of the transmission of pedagogical acts. They are exposed during note-taken or during participations to a pedagogical task and in the multimodality of the communication for example. Every action is organised during the interaction which emerged from the pedagogical relationship.

\subsection{Instrumental approach}

In this section, we will describe the process by which the artifact is transformed into instrument through the use [19]. The artifact is envisaged from its anthropological definition that describes it as any objects (symbolic, tangible and intangible) transformed by the human. The use of a robot put through the construction of schemes produced in the interaction between the student and the properties of the telepresence device, in a particular situation of teaching.

In order to understand how the student apprehends the properties and the function of the robot to reach an action that target a learning activity, we lean ourselves on the instrumental approach of Heidegger [9] and Rabardel [19].
Heidegger indicated that the world and the set of objects are not simply already present, posed there. The individual perceives in the object properties that will enable him do to his action and to achieve his objective. The object does not appear to me for itself, but for his aims. It is the principle of instrumentality. That means that things come to us first through their meaning and relating to our existence. We will select the properties of the object and insert finality, a goal and thus, turn the artifact into instrument for our activity.

This process described by Heidegger, shows the transformation process of the object, about a change in status from artifact to instrument. Nevertheless, the author proposed a unilateral process and neglected transformations that this process brings to the individuals in the use. This has been theorized by Rabardel though his instrumental theory.

Rabardel defines the artifacts as something initially conceived to produce effects and precise results planned by its designers. It is in a dynamic process of construction that the artifact takes the status of instrument, during the use on a user during the activity. In this perspective, the instrument becomes a mediator between the subject and the object which became a way to succeed to this action.

The instrument is defined as "a joint entity which deal with in one hand the symbolic artifact and on the other hand, the use of schemes and, the representations which take part of the user's skills and are necessary for the use of the artifact". [19]

The instrument is elaborated by the actor in the instrumental genesis process which results of an evolution of the instrument lean on transformations which update themselves in a new context. The user appropriate the instrument during the instrumental genesis directed towards the artifact in an instrumentalized process, but also towards the user in an instrumentation process. The instrumentalization underpin on an artifact property which will have a particular status in the action.

The instrumentation processes throwback to the construction and the evolution use schemes emerging in the use. In our case, the instrumentation refers to the process of the robot and its peripherals' appropriation (computer interface, webcam, computer mouse, etc.) as technological instruments.

\section{Question}

The questions that we ask ourselves and which we try to answer through this study are closely related to our professional concerns in our profession of accompanying integration of technologies in education. Indeed, the telepresence robot was first conceived and designed by its designers, to improve 
the user experience in the use of videoconferencing in a company. However, we have chosen to divert this prescribed use and offer it to students who cannot physically go to university.

The hypothesis that we put in this robot object was not to improve a videoconference experience, but to offer students a new form of presence. We did not know if this object would really be adapted for distance learning on full days and on several days. We wonder how futures users could use this robot, the activities and actions they could do and create through their uses.

Therefore, we situate our study in an empirical approach and choose to question the subjective experience of the users. Thus, it is from our encounters with the actors (teachers, students, family circle), within the framework of these accompaniments, that our questions around perception and instrumentalization were born, which we will describe below.

The first question that emerged from our field is that of the definition of this robot object. Proulx [18] writes that it is the use that will give its definition to the object. Heidegger's understanding [9] completes this assertion by saying that it is intentionality that will define and delimit the object. It is true that this robot object has a special status that deserves to be apprehended. New technologies in teaching often aim to improve student learning or to change the teaching practices of teachers in order to advance their students. We wondered then if the use of the robot can influence the learning of a student.

In the description of its characteristics and functions, the robot is not presented from the outset as a medium which participates in the mediation of the teaching and which could be described as interactive media for example [6].

It appears as a neutral artifact which, when it is associated to a specific use [18], doesn't tend to a modification of the relationship to knowledge or to an innovative construction of the teaching. So, it is not presented as a pedagogical object as everyone can understand it. The proposed use in this pedagogical concept designate it as an artifact whose goal is to offer learning conditions by the preservation of a "presence" during the class.

However, Rabardel get opposed to the conception of tools neutrality and stressed that the instrument is not conceptually neutral. [19] The instrument is a vector of resources for the action of the user but also of constraints which will influence the cognitive activity of the user as well as the object of his activity. The robot's properties and its control interface will constrain the students in the actions they do while proposing a space in which they can deploy their strategies to do an action thanks to this new resource.

The telepresence robot allows the students to be present at a distance during a traditional course and offers the possibility to participate to it synchronously. The underlying objective to its use is to offer the opportunity for the learner to deploy different dimensions of his/her presence as described before.

In the face-to-face pedagogical relationship, the subjects developed schemes of presence which by their dynamic characteristics, deploy themselves in the pedagogical relationship and get organised and structured around invariants of the learning situation and in its process. However, Shusterman [20] or Vygotski [22] show that the modalities of presence refer to skills whose intention is implicit and unreflective. The functionalities of the robot allow a verbalization and visualization synchronized and can to some extent allow this implicit in verbal communication.

Nevertheless, the proprioceptive sense that brings to the person some information on the orientation of one's body in space and events of one's body in space (such as the distribution of voice) are not part of the features of robot.

As Merleau-Ponty [16] judge our somatic perception as unintentional and implicit, the use of the robot requires from the pilot that his actions are performed in an attentional, thoughtful and explicit way.

Thus, the main question of our research is to understand how the instrumental genesis process can it include the development of relational and cognitive skills that can be mobilized in a learning situation presence mediated by the robot.

By focusing on instrumental genesis process in which the robot takes the instrument status for learning activity of those three students, we mean other questions, namely:

1. What dimensions of the presence the students may mobilize? What patterns are constructed to express a form of presence?

2. How does this form of presence can affect the learning process of the students and their cognitive activity?

3. What are the specific skills that will be constructed to maintain a state of presence?

4. What are the effects of this form of presence on the pedagogical relationship? 


\section{Method}

\subsection{Presentation of the telepresence device}

Our research deals with the use of a telepresence robot - which is a Beam model (see Figure 1) developed by a Californian company. This robot is endowed with a similar system as the videoconference. It has a thirteen inches' screen, measure sixty-three inches and is installed on wheels.

Moreover, it has two cameras: one for the video with a frontal view and the other one positioned on the direction of wheels to facilitate the piloting. The robot has a set of microphones and loudspeaker which allow a synchronous communication. The robot can move thanks to orders received by the $\mathrm{Wi}$ Fi system.

The sending of the orders is made by the control interface which allows the students to control the robot since her hospital room but also to see the environment and communicate synchronously.

The control interface is installed on the students' computer; their face appears on the robot screen thanks to their computer's webcam.

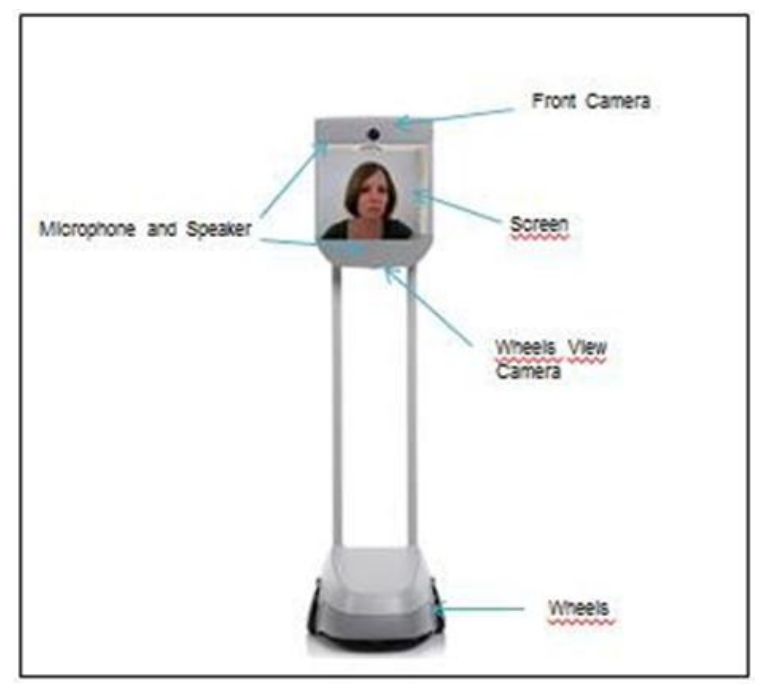

Figure 1. Robot Beam Pro

The control interface (see Figure 2) shows the two visions of the robot's cameras and a screen of its webcam vision. The interface proposes many functions such as the zoom, the adjustment of the microphones and the loudspeaker, the sharing of the screen or information about the battery or the Internet connection.

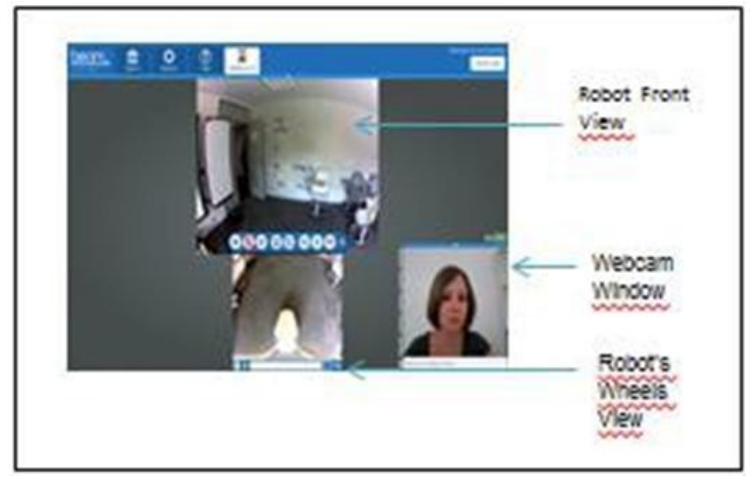

Figure 2. Control Interface

\subsection{Population}

In this part, we will describe the three students we accompanied during their uses of robot between 2014 and 2016. To preserve their anonymity, we will use pseudonyms.

The first student, will be named Quentin, was 21 and he was a first year student. He was hospitalized for two months after an infection in his leg. He was then in remission at home for one month. Just as Hormé, his teachers proposed him a grade repetition. However one of them refused this proposition and asked us to make available the robot to Quentin. He used the robot to participate to a part of his courses during two months, from April 2014 to June 2014.

He was not able to follow all of his courses either because they took place during his care or because of the bad quality of $\mathrm{Wi}-\mathrm{Fi}$ connection in some classrooms. Quentin first piloted the robot from his hospital room, then from his home. In this school, courses always take place in pairs or in group, except for lectures in amphitheater. A friend of Quentin was in charge of accompanying him in the school premises to help him with the robot move. Quentin also used the robot during informal moment, especially for coffee time.

The second student we will describe will be named Hormé, is preparing an IDEA (Innovation, Design, Entrepreneurship and Art) Master at the EMLyon Business School. Hormé is 23 and she was hospitalized during four months at home after a spine surgery which obliged her to stay in a bed without a movement.

The person in charge of the management of this Master firstly wanted Hormé to give up this year to start again the next year. To avoid this grade repetition, we proposed to her and to the manager of the Master, to try the robot.

She used the robot to participate to all her courses during those four months that is to say from October 2014 to the end of January 2015. 
Hormé has piloted the robot since her bed, using her computer which was adapted to her posture (she was oblige to keep lay on her back). We helped Hormé for the installation of the device but also how to use the interface of the robot. The robot was placed on a floor of a building reserved for the students, teachers and people in charge of the IDEA Master. Students have classrooms, a recording studio and diverse informal spaces. Thanks to the robot, Hormé could participate to her courses but also to every informal moment with people who use those spaces.

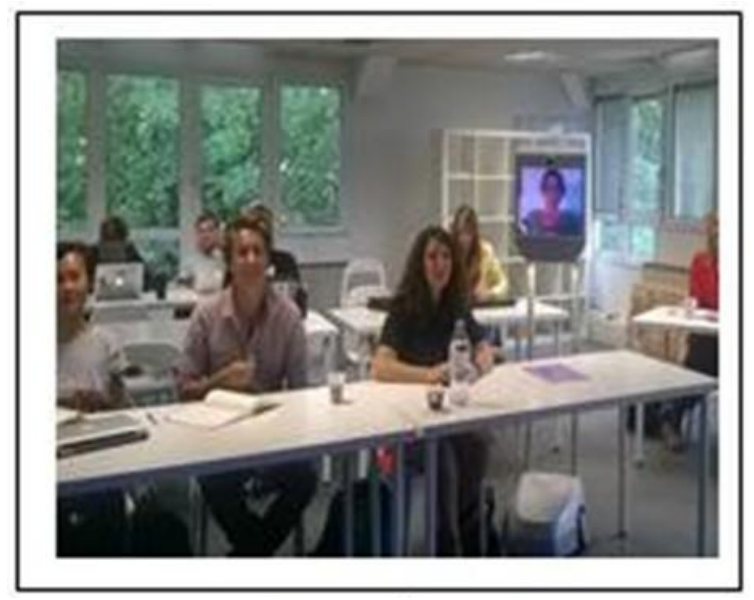

Figure 3. Hormé in Classroom

The third student, will be named Nathan, is a $\mathrm{PhD}$ student. He has been tetraplegic since a skiing accident when he was 20 . He lives at 124 miles (200 $\mathrm{km})$ away from his university which makes it difficult to travel to the campus. Since October 2015, he's using the robot to participate to seminars, conferences and for work meetings.

He was piloting the robot from his home. That kind of robot could be only piloted with hand but Nathan can only move his head, neck and shoulders. We tried to install appropriate software but the robot's proprietary software is so "closed source" that we could not submit any alternative. For this reason, his carer (a life assistant) was driving the robot for him. Nathan gave indications to his carer orally and the latter executed them.

For the three students, we informed the whole pedagogical team about this experimentation and we asked them their agreement about students' participation through the robot. No one refused; teachers were quite enthusiastic and curious about this device.

\subsection{Data collection}

To lead our research, we decided to enlarge our approach with the first and third person. For the third person approach, we chose to position ourselves in the interactionist prospect of the activity in order to observe and to describe pedagogical situations in situ.

Take place in an interactionist approach allows us to access to the objectivables and public data of the activity in order to report the modalities of interaction which emerged in the pedagogical situations mediatized by the robot of telepresence. So, we focus on the one hand on the diverse ways used by the three students, their classmates and theirs teachers to communicate during the courses in which they use the robot. On the other hand, the observation of the activity in situ allows us to apprehend the indications of the different forms of the presence that are linked to interactional skills through the manifestation of the presence.

In order to describe the pedagogical situations and the manifestation of the presence, we lean on non- participative observations instrumented with video recordings of lessons. Concerning Hormé, we filmed three courses of two hours each while she used the robot. These courses were called "project creation of activity". For this, we use an observation grid to take and categorized the observables dimensions of the pedagogical activity.

About Quentin, we filmed four courses of one hour and a half each. It consisted of three directed studies and one practical work. They were called "Electro technical" and "Mechanics of fluids». We have chosen these teaching for both students because of their many categories and they propose activities with an active pedagogy: that allows us to see pedagogical and varied learning acts and, different dimensions of the presence.

We were refused to filmed Nathan's seminars and his work meetings for confidentiality reasons.

The observation grid mentioned the presence of the different actors in the situation, the use of the spaces, the use of the objects, their application and directions, their movement, the interactions, the kind of pedagogical version plus its dynamic and the proposed tasks.

Then, fragments of videos were selected to analyze communication forms (verbal, non-verbal, gesture) which come from interactional skills that we also considered as indications of the presence.

Nevertheless, the interactionist approach of the activity doesn't allow us to reach the cognitive processes deployed by the students during the construction of schemes during the instrumental 
genesis in the use of the robot, nor the effects on the learning process.

Actually, the cognitive dimension is a private and subjective data only explicable by the actor. The cognitive strategies which go through the construction of use's schemes of the robot comes from the intrinsic meaning that we chose to reach thanks to explicitations' interviews led with Hormé, Quentin and Nathan. This kind of interview aims to approach the activity as a lived and subjective experience, by stressing on raise awareness aspects of the experience. This interview brings the subject to express the implicit dimensions (their thoughts or mental activity, sensorial perceptions and emotions) so, things that are not perceptible from the process in the activity.

Moreover, we didn't have the possibility to constitute a video support of the three students 'activity produced from their own "direct" space (Their hospital bed, their home), during the use of the interface and of the peripheral tools. So, we can't infer mental activities from actions produce with the telepresence device.

We did an individual explicitation interview with Nathan in March 2016, so after five months of utilization. We also did two individual's explicitations' interviews with Quentin and with Hormé. Concerning Quentin, the first interview was conducted after two weeks of utilization (at the end of April 2014) and the second at the end of the utilization (in June 2014). For Hormé, we did the first interview after a week of use of the robot (in October 2014) and the second one after four months of use (beginning of February 2015). The aim is to apprehend cognitive processes deployed by our students to attain learning acts and reach the subjective dimension of the learning. The interviews took place at their home and lasted between one hour and a half and two hours each.

These two interviews, located at the beginning and the end of the use of the robot, report the dynamic process of appropriation of the robot and of elaborate schemes during the phase of instrumentalization by which they could develop skills linked to the dimensions of the presence. Interviews also focused on perception and subjective experience.

To reach the subjective dimension of the teacher's activity and how this dimension is translated in the pedagogical relation which is mediatized by the robot, we did auto-confrontations' interviews coming from the theoretical approach of the action course of Theureau [21]. Those interviews had been led with three teachers whose courses have been filmed and a post activity interview with two teachers whose course cannot have been recorded.
The video recording and the analysis grid have here a function of support in the evocation during the post activity interview led with the teachers to clarify in a reflexive posture, the cognitive processes at work during the performance of educational actions and in "conscientisables" aspects of interaction.

\section{First results}

We will present here our first results, which we will classify into two categories: the first is related to the actions mediated by the robot, highlighting what the students can or cannot do and how they adapt in situation. In the second category, we will bring the first elements of comprehension of the effects of students 'presence through the robot, on the pedagogical relationship.

\subsection{Robot-mediated actions and adaptation strategies}

Our first results deal with cognitive strategies deployed by Hormé on indication of interactional modalities faced in pedagogical situations.

During explanations given by the teacher, or during the transmission of theoretical contents, Hormé firstly tried to take written notes: "I could not take notes because it was too complicated. So I was really concentrating on was the teacher was saying and I was trying to think at the same time about what he was saying and I was making memo-technical stuff at the same time. I had to make this effort because I had no written traces of the course." During this first movement, she firstly confronted her actions' schemes elaborated during previous situations which she at first thoughts similar. However, her schemes were deployed in a traditional teaching context. And, the organization of her work area and the use of her hands to command the control interface did not allow her to take note.

Here, the constraints bound to the robot properties prevented the adequacy of the pre-existent schemes and caused an imbalance in the action structure. According to Hormé, her written notes take the status the mnesic and metacognitive support that she will stock and get back subsequently. She had to identify the constraints linked to the instrument to get free with it and she had to use the instrument resources to deploy cognitive strategies of learning adapted to the situation and also metacognitive strategies.

In order to overcome the absence of writing, Hormé describes a high level of attention and concentration on explanations and interventions spread during the class, while apply a thought on her own methods to memorize something. 
To facilitate her comprehension of the pedagogical content, Hormé explains that she asked teachers and the other students more questions than usually in a classic situation.

However, she describes this action as a difficult operation. Firstly, the absence of proprioception prevented to her to have a return on the volume of her voice. The classroom social rules defined a sound level and the violation of this rule produce a negative reaction on the group and can put the person, who disturbs intentionally the group, in an uncomfortable way. Consequently, she did not speak enough loudly and wasn't heard or she turned her microphone's volume up but the sound disturbed the group and Hormé was in an uncomfortable situation.

Finally, during spontaneous request, she preferred to be remarked by the teacher by moving her hand in front of the camera or making the robot move - she describes this method as effective.

During works in small groups, Hormé can maintain spontaneous requests with a verbal communication when her microphone was adjusted at the beginning of the activity of the group.

Her participation and contribution to this activity required a modification and an adaptation of Hormé and her classmates' actions. Indeed, the participation to the common elaboration of a written project, diagram or draw or diverse material and digital technology resources creation, required the exchange of mails between her group and herself, but also visits at her home when the object could not be digitized.

Quentin has encountered difficulties to see what was written on the white board and despite the fact that he was using the zoom, he could not see clearly the mathematical formulas and the theoretical data inscribed by teachers. He first tried to zoom in and move the robot to search for an appropriate position, but these actions were not sufficient. He finally chose to ask to his partner to describe to him the formulas and data. He also listened carefully the teacher speech and sought to identify the most important idea in order to understand the course content: "I try to listen to the key lines and after that, I ask Carles [his partner] to spell out the steps". In this situation, Quentin first wanted to use the zoom function as an instrument as similar as human eyes. He also tried to move the robot to see more clearly, as he would have done naturally with his body. Because he cannot use directly his own perception with the robot, he decided to use his partner's one. Furthermore, this situation required him to do an additional cognitive effort to select the information given orally by the teacher. Working in pairs has facilitated adaptation to this context and allows getting around the difficulties of perception.
Just like Hormé, Quentin has no proprioceptive returns of the volume of his voice: "There is always this problem, I don't know how strong I talk loud through the robot so I can't whisper (...) so now, we understand each other, Carles and I : when I turn to him, he understands that it's because I would like to speak to him." This communication strategy has been developed intersubjectively between Quentin and Carles to achieve their activity despite of the technical limits.

Finally, Quentin explained that the fact of being able to work on the same subject, on the same time as his comrades and interact to them, have contributed to give a sense of presence : "It's as if I was really there with them".

Concerning Nathan, the main action that the robot allows him to do is to participate in conferences in distant cities without having to move: "journeys are tiring and I can put several days to recover, that's why I have to select whish conference I could attend or not, just because of the travel."

The robot also allows Nathan to meet researchers and to interact with them and with professionals in his field, during informal times. He explained that these meeting are essential in the activity of researcher. With the robot, Nathan can follow them to the coffee time or walk in the corridors with a colleague and talk with him one-to-one.

Nathan can both meet people and participate in exchanges in a group and, at the same time, he can get away if he feels the need. Indeed, Nathan explains to us that he is shy and he feels the need to get away himself from the group sometimes: "I am a little bit shy so the fact that the robot can move, this allows me to slip away for a few moments and to come back (...) It's nice to put myself forward and to blend into the backgrounds if needed."

Nathan can interact with others researchers and create a network, which is an important part of a doctoral student's activity. These exchanges usually take place under informal space and time and the mobility offered by the robot allows Nathan to accomplish them.

Moreover, the last observed result intrigued us: when Nathan is using the robot, he can both preserve a form of presence and at the same time, he can keep a distance to respect a personal well-being, without completely cutting the relationship. By appropriating the robot, Nathan was able to regulate a level of presence-distance that he wishes to establish in informal 'encounters places.

\subsection{Pedagogical relationship}

After emphasized the main actions that students can or cannot produced with the robot, we will 
present here the first results concerning the effects of the use of robot under pedagogical relationship.

The first results are quantitative and come from our filmed observations. They concern the interaction between teachers and students with the robot. The observation of the courses situations and the interviews' analysis show us that the teachers' requests are more frequently directed towards students with robot than towards her classmates. This tendency decrease after the first thirty minutes of the course. Those demands concerned principally their visual and hearing comfort but also their wellcomprehension of the teacher's speech.

We also observed that teachers only pronounced the name of students with robot and never those of students in the classroom. During interviews, four teachers says that they were embarrassed because they didn't know toward where the attention of the student was directed and if they really following the course. Usually, we call someone with his name if that person is not there or to get her attention. In this context, teachers didn't know if students with robot were attentive to the courses or not, that would explain why teachers pronounce the name of the students which used the robot and not those of the others students.

This first result brings us to another data concerning the access to the territory of the other. Pedagogical relationship is asymmetrical because of the role of each party, but this context of remote presence through a robot adds an asymmetry. Indeed, teacher and student (with robot) do not share the same "direct" space and their interactions are still mediated by a machine and this situation has two consequences:

Firstly, the principle of reciprocity of access to the territory of each is not respected. A Quentin teacher told us: "With Quentin, I absolutely cannot know what is doing (...) It's normal for the student that a teacher has access to his screen and he is not supposed to do secret thing and here, I don't know what he is doing." Another Quentin teacher said that he usually circulates toward his students to look at their work in order to see how they are doing and to help them if needed, but he cannot do that with Quentin: "I can't help him and in addition, he never asks me questions (...) My problem in relation with that, it's also the fact that I can't see if he's working or if he's doing something else on Internet and it's not normal." The teacher does not have access to his student's territory; therefore, he is not in a position to watch over the activity of his student or to help him. Nor can it ensure compliance with the rules of procedures of the class.
Secondly, we also noticed new teaching practices: during the interviews led with the teachers, we asked them if they had already rolled out individualized actions towards absent students. Everyone answered that they have no concerned for students who cannot follow courses. Every teacher we had meet since the beginning of this experimentation, or in similar experimentations, they all declared: "They manage themselves alone".

However, during the interviews, the teachers told us about different individual practices such as the following examples: the teachers have sent the gathered resources - before or after the course - to students in an e-mail. About Hormé, during the viewing of a video in a class, the teachers explain they also have sent it to Hormé in order to be sure that she could correctly see it. Then, a teacher proposed to Hormé an individual teaching - when she missed a lesson during her surgery - through the robot.

The use of the robot in a traditional teaching context, brings the actors (teachers and students present via the robot) to develop strategies to maintain a co-presence that is both cognitive and pedagogical.

The fact that the student is present via the robot induces a form of commitment on the part of the teacher. The teachers questioned modify their practices by adapting them to the form of presence of the student. Indeed, teachers do not deployed the same practices as with physically present students and they do not leave them alone, as they do with absent students. This form of student presence via the robot is an opportunity for a compromise in teaching practices.

Nevertheless, this compromise does not seem completely satisfactory, from the point of view of the teacher. The absence of territorial sharing does not allow the teacher to access the student's activity or his productions. This asymmetry makes it difficult if not impossible for the teacher, to propose a form of pedagogical presence and to accompany the student in his learning activity. Moreover, he is not able to apply his authority to the student, as far as life outside the classroom is concerned, and according to the teachers interviewed, there is no need to be inside of the class (surfing the internet, sending text messages, etc.). Teachers have no power over the actions of the student and cannot know where the attention of the student is directed.

The possibility for the teacher to apply his authority to his students is questioned here. We believe that this may affect the acceptability of the robot by teachers. 


\section{Conclusion}

The introduction of technologies in the teaching is reconsidering the concepts of the presence and the absence. The use of telepresence device by an hospitalized student who participates at distance and synchronously to a traditional teaching, help us to ask ourselves about the meaning of the presence in the higher education.

In this study, we interested to how a telepresence robot allows students who cannot be physically attending a course and that for health reasons, to participate to the lessons and the school life around him or her, by the manifestation of presence's forms.

The presence of a student in a course cannot be simply considered as a physical presence and recordable as a unity. Previous surveys in Human Sciences show that the presence manifests itself through different forms and mobilize the individual to several subjective levels: affects, emotions, mental activities, perceptions, and so on. The student presence to the other manifests itself through signs, indications which are deployed in relationship and interactions between the students and the teacher.

The organization of the interaction refers to interactional skills. These skills are socially built; they tend to give to the others some indicators to support the comprehension of the communication but also bringing significations to events which appear in the environment. These skills are fundamental for the participation to the life of the group. In the education context, the student presence appears with the verbal or non-verbal communication, the gesture and movements which are a set of schemes structured during an interaction and in the pedagogical relation and which facilitate the construction of knowledge.

Whereas these presence modalities are practiced non- intentionally and implicitly in a traditional faceto-face context, the use of a telepresence robot to participate to courses needs the control of commands to issue actions in the classroom which is located far from the student.

In this research, we considered the telepresence device (the robot, software of piloting, computer, etcera) as an instrument in the sense of Rabardel, whose use produced effects on the learning modalities of students, their relationship with peers, on their cognition as well as on their pedagogical relationship. Through the instrumental genesis process, the artifact robot will take the status of instrument in the students' activity. So then, it is well and truly the student who will transform the artifact robot as an instrument for their own activity, by an instrumentalization and instrumentation processes: this process corresponding to an appropriation of the device by a student. We want to understand how, in the instrumental genesis, a student who uses the robot can elaborate schemes linked to presence manifestations.

We wish to conduct our observations on the development of the uses in order to observe the effects of the instrumentation on its learning processes and how the pedagogical relationship evolves.

To apprehend its effects, we chose to be in an interactionist approach of the activity by a nonparticipant observation filmed during some courses during which the students, who were hospitalized, used the robot to participate to their lessons. This method let us seeing observable indications of the presence and its manifestations in the interaction. Nevertheless, to reach the subjective dimension which deals with the cognitive processes in the construction of the used schemes during the utilizations of the robot and their effects on the cognition, affects, thoughts of the student and the teachers, we chose to conduct some interviews "postactivity".

This research is part of our thesis work and the results are not yet completed. However, the first data allow us to present some results concerning the instrumentation process but also the pedagogical relationship.

Indeed, data show that the confrontation of schemes deployed by students, during teachings when they were present with the telepresence device, was unsuccessful because of an incompatible execution of the schemes elaborated in previous experiments, which set them in an imbalance situation [22]. The properties of the device needed to be included in the schemes construction adapted to this new situation to transform those actions.

Moreover, it seems appeared that the pedagogical presence is promoted by the teachers' engagement in the role they play in the accompanying of the student's cognitive processes and in the expansion of new pedagogical practices to respond to the difficulties caused by the physical distance of these students. Nonetheless, this situation seems to modify the role of the teacher but also of the student. Indeed, we observed that on the one hand, teacher loses direct access to the student's activity and thus, the control of his actions, which can hinder his authority. On the other hand, by opening access to course resources and soliciting the student, teacher promotes cognitive presence of the students.

Those results are a premise of the research and if we want to describe the signs of the presence in the teaching, we have to describe teaching situations without the use of the robot in order to recognize the situations' invariants and to categorize them. 
Furthermore, we could realize a similar approach with teachings in which a student uses the robot in order to compare the invariants. This approach which would be at the same time qualitative and quantitative - allows us to show the presence signs when it is mediatized by the robot. Moreover, we could recognize much better and go deeper in the interpretation of the indications of the interactional skills and their evolution in the instrumentation processes.

\section{References}

[1] Blandin, B. (2004). La relation pédagogique à distance: que nous apprend Goffman? Distances et Savoirs, 2(2-3), 357-381.

[2] Breton, D. L. (2014). Le corps entre significations et informations. Hermès, La Revue, $\mathrm{n}^{\circ}$ 68(1), 21-30.

[3] Chemla, P., \& Shusterman, R. (2010). Conscience soma- esthétique, perception proprioceptive et action. Communications, 86(1)

[4] Cosnier, J. (1997). Sémiotique des gestes communicatifs. Nouveaux actes sémiotique, 52, 7-28.

[5] Courtial, J.-P. (2009). Connaissance et conscience par couplage biocognitif. Bulletin de psychologie, Numéro 500(2), 149-159.

[6] Duplàa, E. (2004). Imaginaire, corps et instruments dans la relation pédagogique à distance. Distances et Savoirs, 2(2-3)

[7] Garfinkel, H. (2007). Recherches en ethnométhodologie. Paris : PUF.

[8] Goodwin, C. (2007). Participation, stance and affect in the organization of activities. Discourse Society, 18, 53-73

[9] Heidegger, M. (1958). Essais et conférences. La question de la technique. París. Ed. Gallimard

[10] Henri, F., Compte, C., \& Charlier, B. (2007). La scénarisation pédagogique dans tous ses débats.... Revue internationale des technologies en pédagogie universitaire, 4(2), 14-24.

[11] Houssaye, J. (1988). Théorie et pratiques de l'éducation scolaire. Berne; New York: P. Lang.

[12] Jézégou, A. (2008). Apprentissage autodirigé et formation à distance. Distances et Savoirs, 6(3), 343-364.

[13] Jézégou, A. (2010). Créer de la présence à distance en e- learning. Distances et savoirs, Vol. 8(2), 257-274.

[14] Le Breton, D. (2014). Le corps entre significations et informations. Hermès, La Revue, 68(1), 21-30.
[15] Maturana, H. R., \& Varela, F. J. (1991). Autopoiesis and Cognition: The Realization of the Living. Springer Science \& Business Media.

[16] Merleau-Ponty, M., \& Smith, C. (1996). Phenomenology of Perception. Motilal Banarsidass Publishe.

[17] Minsky, M. (1980). Telepresence. Omni. (pp. 45-51).

[18] Proulx, S. (2005). Penser les usages des TIC aujourd'hui : Enjeux, modèles, tendances. In L. Vieira, \& N. Pinède (dir.). Enjeux et usages des TIC : Aspects sociaux et culturels. Tome I (p. 7-20). Bordeaux, Presses universitaires de Bordeaux.

[19 Rabardel, P. (1995). Les hommes et les technologies : Une approche cognitive des instruments contemporains. Paris : Armand Colin.

[20] Shusterman, R. (2010). Conscience soma-esthétique, perception proprioceptive et action. Communications, 86(1), 15-24.

[21] Theureau, J. (2010). Les entretiens d'autoconfrontation et de remise en situation par les traces matérielles et le programme de recherche «cours d'action ». Revue d'anthropologie des connaissances, Vol 4, 2(2), 287.

[22] Vygotski, L. S., Piaget, J., Sève, L., \& Sève, F. (1985). Pensée et langage. Paris: Messidor Éditions sociales. 